
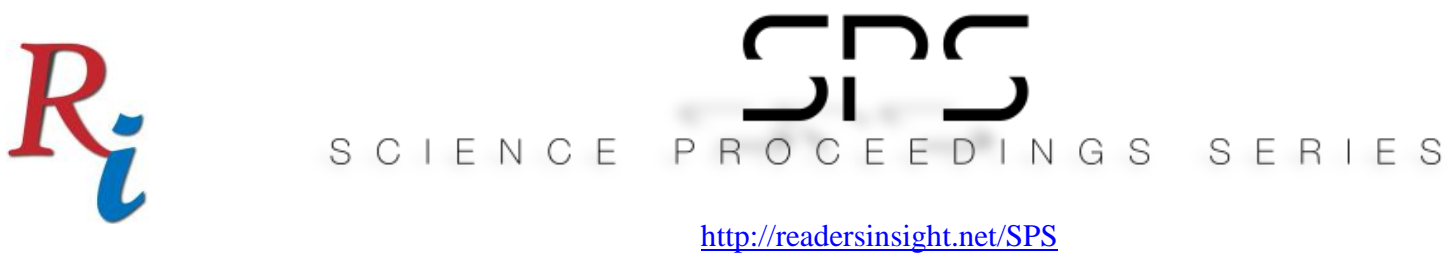

\title{
IONIC LIQUID-STABILIZED FOAMS IN RELATION TO ENHANCED OIL RECOVERY
}

\author{
Asyimah Asri \\ Department of Petroleum Engineering \\ Universiti Teknologi PETRONAS, Seri Iskandar, Perak, \\ Malaysia \\ Rashidah M. Pilus* \\ Department of Petroleum Engineering \\ Universiti Teknologi PETRONAS, Seri Iskandar, Perak, \\ Malaysia \\ Ahmad Kamal Idris \\ Department of Petroleum Engineering \\ Universiti Teknologi Malaysia, Skudai, Johor, \\ Malaysia

\section{Ismail Mohd Saaid} \\ Department of Petroleum Engineering \\ Universiti Teknologi PETRONAS, Seri Iskandar, Perak, \\ Malaysia

\section{Zakaria Man} \\ Department of Chemical Engineering \\ Universiti Teknologi PETRONAS, Seri Iskandar, Perak, \\ Malaysia \\ Abdelazim Abbas Ahmed \\ Department of Petroleum Engineering \\ Universiti Teknologi PETRONAS, Seri Iskandar, Perak, \\ Malaysia
}

*Corrosponding author's Email: rashidah mp@utp.edu.my

Peer-review under responsibility of 4th Asia International Conference 2020 Scientific Committee http://connectingasia.org/scientific-committee/ (C) 2020 Published by Readers Insight Publisher, lat 306 Savoy Residencia, Block 3 F11/1,44000 Islamabad. Pakistan, editor@readersinsight.net 

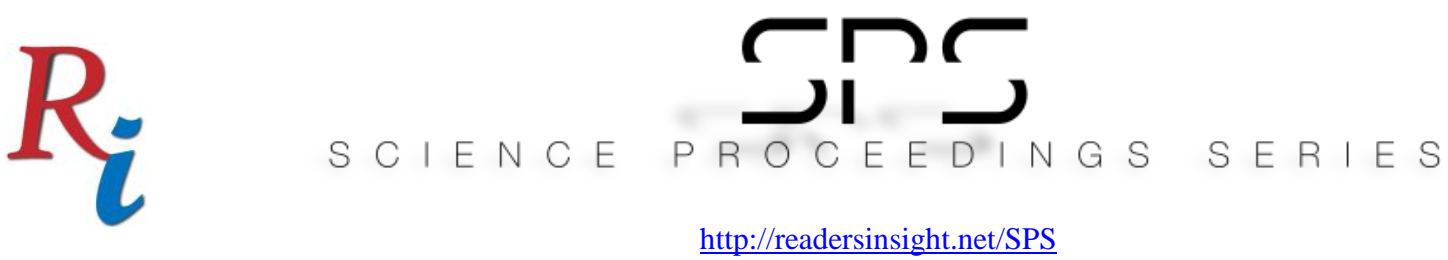

\section{A b s t r a c t}

Foam stability is unfavorably influenced by crude oil and this situation has been a main obstacle for the foam injection application for enhanced oil recovery (EOR) $(1,2)$. The presence of additives to surfactant solution could improve foam stability $(3,4)$. In this work, effectiveness of the common ionic liquid (IL) and newly developed eutectic-based IL or known as Deep Eutectic solvent (DES) were determined to evaluate their use as co-surfactant in stabilizing foam in the presence of oil. The novelty of the new chemicals in EOR application is in its capability to enhance the surfactant performance in foam stability while being cheap, biodegradable and easy to produce for bulk application. Several formulation of IL/surfactant mass ratio were investigated based on bulk foam stability test in the presence of oil to find the optimum formulation. A fixed concentration of an in-house-surfactant, MFOMAX (M) was utilized. Core flood experiments were performed to evaluate mobility reduction factor (MRF) and incremental oil recovery. The overall results demonstrated that the addition of ILs in surfactant solution were found to improve foam stability. Increment in MRF value and additional oil recovery (AOR) were also reported.

Keywords: Surfactant, Ionic Liquid, Additive, Foam Stability, EOR

\section{Rese a r ch H igh I ight s}

1. The new cost-effective ionic liquid as foam additives have been introduced. The presence of ILs were able to enhance M surfactant in stabilizing foam.

2. Based on bulk foam stability in the presence of oil, optimum surfactant/IL mass ratio varies, depending on the surfactant/IL types.

3. The capability of DES was comparable to that common IL at their best formulation.

\section{Research Objectives}

The purpose of this study is to access the effectiveness of two groups of ILs, common ILs and eutectic-based ILs, as additive in improving surfactant performance on foam stabilization. This study is necessary to evaluate the ability of these chemicals to in gas mobility control and EOR. Previous work by Hanamertani et al. (2018) was only limited to gas mobility control without oil to independently understand the mechanism of chemical stabilization and propagation of foam without further study on oil recovery (5). Hence, the capability of ILs-foam in enhancing oil recovery in this study is the ultimate objective to evaluate whether ILs is able to minimize the well-known limitation of foam; foam destruction as being contact with oil, and to investigate whether a stable foam is the main aspect to enhance oil recovery. 

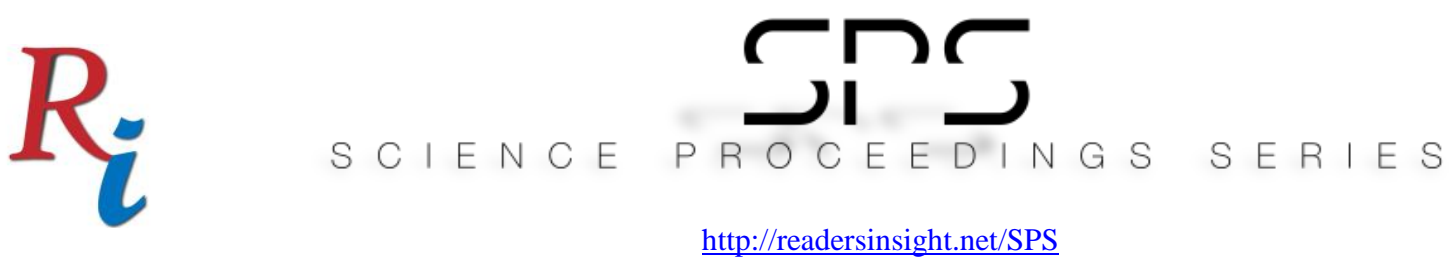

\section{Methodology}

A constant surfactant concentration of $0.5 \mathrm{wt} . \%$ was prepared as a base case solution, whereas the additives concentrations were varied. Two types of ILs were investigated in this study. 1butyl-3-methylimidazolium trifluoromethane sulfonate, IL4 represented as common IL and Choline Chloride - glycerol (1:2), IL11 represented as DES. The mixtures were added with 3.3 wt.\% salinity of synthetic brine solution. Light Malaysian crude oil was from Baronia field. The bulk foam stability test with oil using Foamscan instrument at $90^{\circ} \mathrm{C}$ was perfomed to find the best surfactant/IL formulation indicated with longer half-life time prior to core flood experiments under reservoir conditions. The amount of mixture solutions $(60+/-1 \mathrm{ml})$, and $10 \%$ of oil $(6 \mathrm{ml})$ were mixed by a constant $\mathrm{N} 2$ gas flow rate $(50 \mathrm{ml} / \mathrm{min})$. Next, HTHP Core Flooding System from Sanchez Technologies (France) was used to represent field application. Three runs had been conducted where the base case experiment was only on $\mathrm{M}$ (the solution without additive). The purpose is to evaluate the additives performance to influence foam stability, increment in MRF and oil recovery. This experiment was performed at $90^{\circ} \mathrm{C}$ with a backpressure of $1800 \mathrm{psi}$ at the end of the holder to simulate the formation pressure.

\section{Results}

Foam half-life for all the samples is plotted in Figure 1. The most stable foam (optimum formulation) in the presence of oil of IL4 (common IL) and IL11 (DES) is at 90:10 and 80:20, respectively.

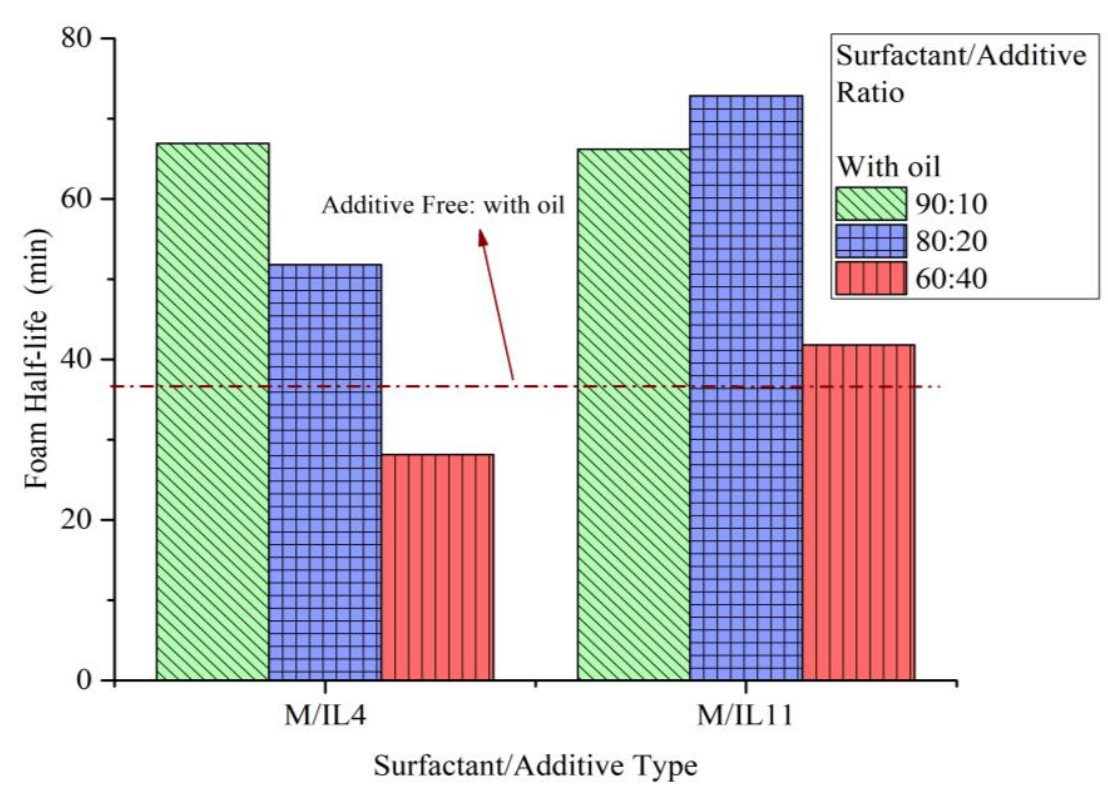

Figure 1: Foam half-life presented by M/IL mixture solutions at different ratios

Copyright $\odot 2020$ Authors. This is an open access article distributed under the Creative Commons Attribution License, which permits unrestricted use, distribution, and reproduction in any medium, provided the original work is properly cited. 

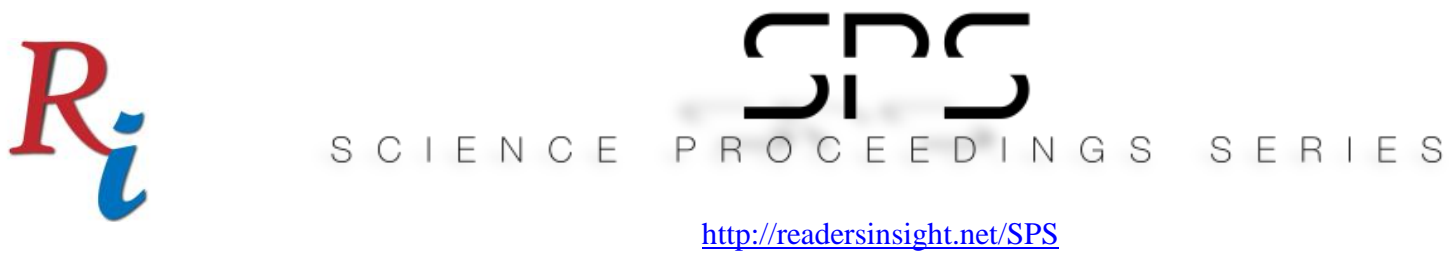

Figure 2 presented the MRF profiles for the base case (M surfactant in the absence of additive) and both type of additives at their optimum formulation. The maximum MRF value for $\mathrm{M}$, M/IL4 and M/IL11 was about 11.50, 11.90 and 13.65, respectively. The addition of small amount of common IL which is $556 \mathrm{ppm}$ of IL4 in M solution can increase the oil recovery up to $10.62 \%$ of OOIP after foam flooding. For DES, higher amount is required to be comparable with the expensive common IL which is about $1250 \mathrm{ppm}$ of IL11, and the oil recovery up was to $9.72 \%$ of OOIP. As for M itself, the increment of oil recovery was up to $8.62 \%$ of OOIP.

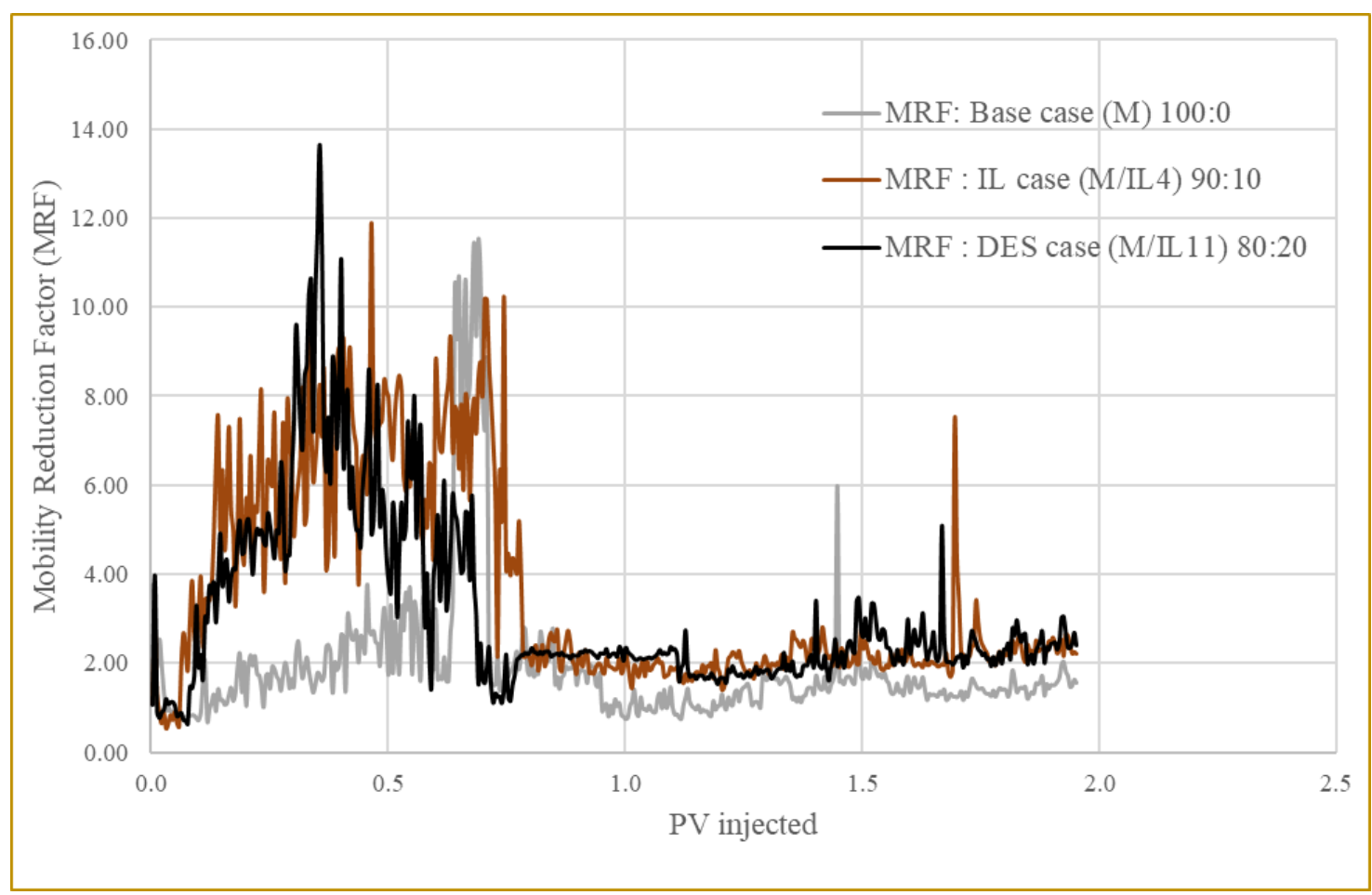

Figure 2: MRF profiles of M 100:0, M/IL4 90:10 and M/IL11 80:20

\section{Findings}

MRF was noticeably increased due to the presence of ILs in surfactant solution. This shows the existence of strong and stable foam inside the core in the oil environment which reduce the gas mobility afterwards improve oil recovery. Eventhough the maximum MRF for M/IL4 was slightly lower than that of M/IL11, the early increment in MRF and its sustainability has led to comparable effect in improved oil recovery with M/IL11. The common IL needs lower concentration as compared to DES to achieve comparable performance which is encouraging as common ILs are normally more expensive. 


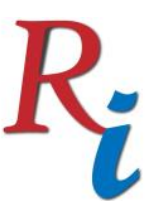

$S C \mid E N C E$

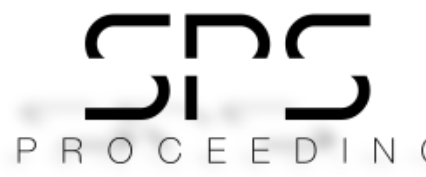

http://readersinsight.net/SPS

\section{Acknowledgement}

We acknowledge the SHELL-UTP-TU-Delft collaboration project for granting research funding under Grant No. 0153 AB-DA3 and acknowledge PETRONAS Research Sdn. Bhd. (PRSB) for supplying the materials. We also acknowledge the Centre of Research in Enhanced Oil Recovery (COREOR), Universiti Teknologi PETRONAS for the technical assistance and laboratory facilities.

\section{REFERENCES}

[1] Farajzadeh R, Andrianov A, Krastev R, Hirasaki G, Rossen WR. Foam-oil interaction in porous media: Implications for foam assisted enhanced oil recovery. Advances in colloid and interface science. 2012;183:1-13.

[2] Farzaneh SA, Sohrabi M. Experimental investigation of CO 2-foam stability improvement by alkaline in the presence of crude oil. Chemical Engineering Research and Design. 2015;94:375-89.

[3] Hanamertani AS, Pilus RM, Manan NA, Mutalib MIA. The use of ionic liquids as additive to stabilize surfactant foam for mobility control application. Journal of Petroleum Science and Engineering. 2018.

[4] Lai K, Dixit N. Foams: Theory, Measurements, and Applications, eds. RK Prudhomme and SA Khan, 57, 315. Surfactant Science Series, Marcel Dekker, New York. 1996.

[5] Hanamertani A, Pilus R, Manan NSA, Ahmed S, Awang M. Ionic Liquids Application in Surfactant Foam Stabilization for Gas Mobility Control. Energy \& Fuels. 2018;32(6):6545-56. 